\title{
Selective Manganese-Catalyzed Dimerization and Cross-Coupling of Terminal Alkynes
}

\section{Stefan Weber, ${ }^{1}$ Luis F. Veiros, ${ }^{2}$ and Karl Kirchner*, 1}

${ }^{1}$ Institute of Applied Synthetic Chemistry, Vienna University of Technology, Getreidemarkt 9, A-1060 Vienna, AUSTRIA

2 Centro de Química Estrutural and Departamento de Engenharia Química, Instituto Superior Técnico, Universidade de Lisboa, Av Rovisco Pais, 1049-001 Lisboa, PORTUGAL
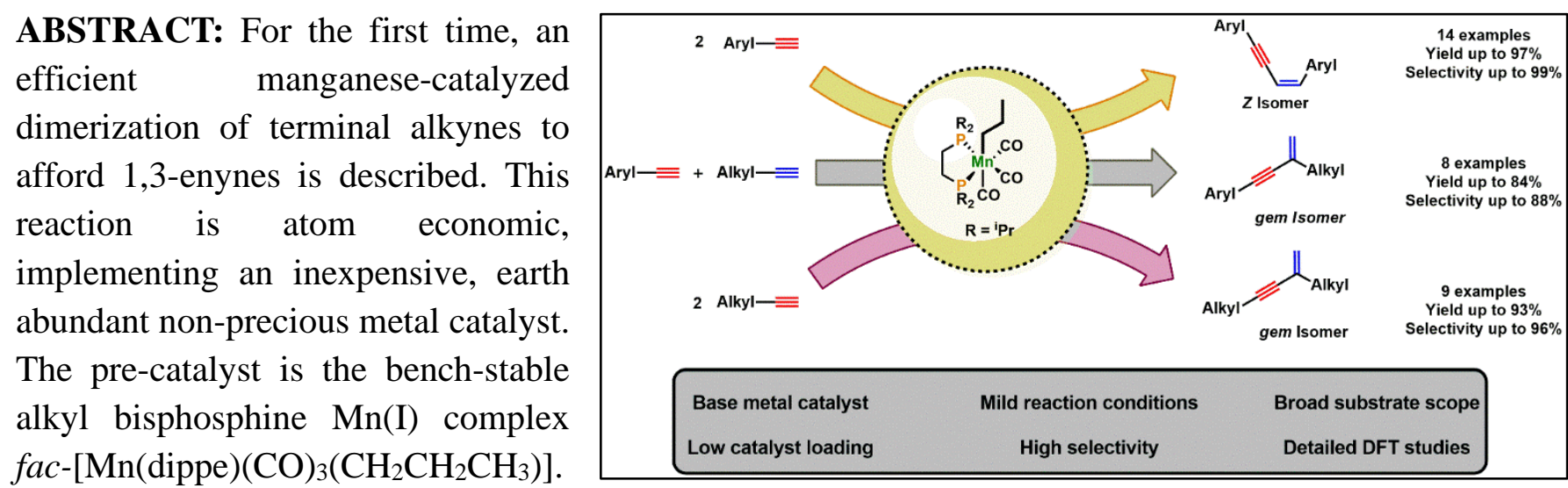

The catalytic process is initiated by migratory insertion of a CO ligand into the Mn-alkyl bond to yield an acyl intermediate which undergoes rapid $\mathrm{C}-\mathrm{H}$ bond cleavage of the alkyne forming an active $\mathrm{Mn}(\mathrm{I})$ acetylide catalyst $\left[\mathrm{Mn}(\right.$ dippe $\left.)(\mathrm{CO})_{2}(\mathrm{C} \equiv \mathrm{CPh})\left(\eta^{2}-\mathrm{HC} \equiv \mathrm{CPh}\right)\right]$ together with liberated butanal. A range of aromatic and aliphatic terminal alkynes were efficiently and selectively converted into head-to-head Z1,3-enynes and head-to-tail gem-1,3-enynes, respectively, in good to excellent yields. Moreover, crosscoupling of aromatic and aliphatic alkynes yields selectively head-to-tail gem-1,3-enynes. In all cases, the reactions were performed at $70{ }^{\circ} \mathrm{C}$ with a catalyst loading of $1-2 \mathrm{~mol} \%$. A mechanism based on DFT calculations is presented.

\section{INTRODUCTION}

CO ligands in Mn(I) alkyl carbonyl complexes are known to undergo migratory insertions to form highly reactive coordinatively unsaturated acyl complexes which can be trapped in the presence of strong field ligands such as $\mathrm{CO}$ or tertiary phosphines - $a$ well-known textbook reaction. ${ }^{1}$ The classic reaction is the formation of $\mathrm{Mn}(\mathrm{CO})_{5}\left(\eta^{1}-\mathrm{COCH}_{3}\right)$ from $\mathrm{Mn}(\mathrm{CO})_{5}\left(\mathrm{CH}_{3}\right)$ in the presence of $\mathrm{CO}^{2-4}$ On the other hand, these acyl $16 \mathrm{e}^{-}$intermediates can be utilized to activate dihydrogen, possibly also molecules featuring weakly polar E-H (E = e.g., C, Si, B) bonds. For instance, dihydrogen is able to react with transition-metal acyl complexes to afford aldehydes and metal hydride complexes. This process is accompanied by $\mathrm{H}-\mathrm{H}$ and metal- $\sigma-C$ bond cleavage and is typically the final step in both stoichiometric and catalytic hydroformylations of alkenes (Scheme 1). ${ }^{5,6}$ 
Scheme 1. Formation of a Mn(I) Hydride and Acetylide Species via Alkyl Migration followed by Aldehyde Release upon E-H Bond Cleavage

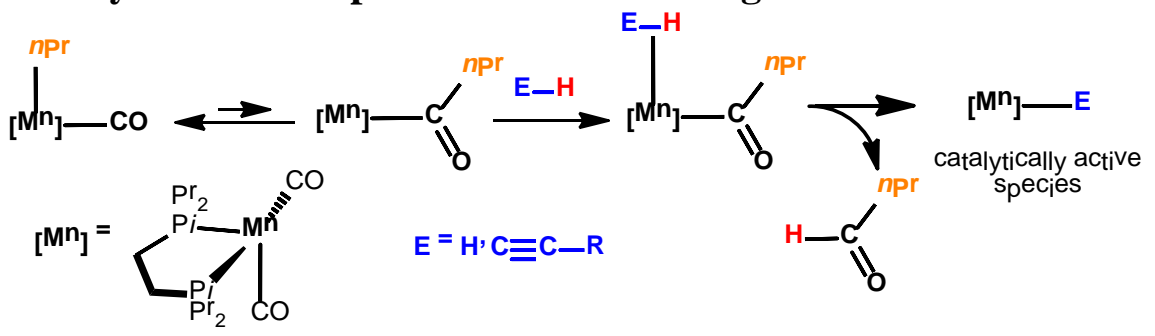

We have recently described the hydrogenation of alkenes and nitriles utilizing $\mathrm{Mn}(\mathrm{I})$ complexes fac$\left[\mathrm{Mn}(\mathrm{dpre})(\mathrm{CO})_{3}(\mathrm{R})\right]$ (dpre = 1,2-bis(di-n-propylphosphino) ethane, $\mathrm{R}=\mathrm{CH}_{3}, \mathrm{CH}_{2} \mathrm{CH}_{3}, \mathrm{CH}_{2} \mathrm{CH}_{2} \mathrm{CH}_{3}$ ) and fac-[Mn(dippe)(CO) ${ }_{3}\left(\mathrm{CH}_{2} \mathrm{CH}_{2} \mathrm{CH}_{3}\right)$ (dippe = 1,2-bis(di-iso-propylphosphino)ethane) where we took advantage of the migratory insertion and hydrogenolysis processes to create the active $16 \mathrm{e}^{-} \mathrm{Mn}(\mathrm{I})$ hydride catalysts (Scheme 1$){ }^{7}$

Here, we describe the activity of fac-[Mn(dippe)(CO) $\left.)_{3}\left(\mathrm{CH}_{2} \mathrm{CH}_{2} \mathrm{CH}_{3}\right)\right]$ (1) as pre-catalyst for the dimerization of terminal aromatic and aliphatic alkynes to afford selectively head-to-head Z-1,3-enynes and head-to-tail gem-1,3-enynes, respectively. The initiation step involves $\mathrm{C}-\mathrm{H}$ bond activation of the terminal alkyne forming an active $\mathrm{Mn}(\mathrm{I})$ acetylide catalyst together with free butanal (Scheme 1). This is the first example of a manganese catalyzed dimerization and cross coupling of terminal alkynes, ${ }^{8,9}$ which proceeds without any additives under mild conditions.

\section{RESULTS AND DISCUSSION}

The catalytic performance of $\mathbf{1}$ was first investigated for the dimerization of phenylacetylene as model substrate. Selected optimization experiments are depicted in Table 1 . With $\mathbf{1}$ as pre-catalyst and a catalyst loading of 2 mol\% quantitative formation of 1,3-enyne was observed at $70{ }^{\circ} \mathrm{C}$ (Table 1, entry 1). No reaction took place with complexes 2 and 3 (Table 1 entries 2 and 3) emphasizing the crucial role of the alkyl substituents at the phosphine donors. It should be noted that high selectivity towards the formation of the Z-isomer ( $>95 \%$ ) is attributed to the use of $\mathbf{1}$ as catalyst, where only small amounts of $E$-isomer $(<5 \%)$ and no formation of geminal isomer were detected. Upon optimization reactions (for details see SI), the catalyst loading could be decreased to $1 \mathrm{~mol} \%$ (Table 1, entry 6). Only traces of product could be detected at room temperature (Table 1, entry 7).

Having established the optimized reaction conditions, a broad variety of different aromatic substrates was investigated. Excellent yields could be achieved for substrates containing a halide or an electron withdrawing-group in the para- or ortho-position (Table 2, 5-7, 12 and 13). Slightly lower yields were achieved for aryl-substrates, containing electron-donating groups such as alkyl- or methoxy-groups (Table 2, 8-11). Amine functionalities are tolerated (Table 2, 14, 15 and 17), however, the reactivity of the system is decreased. Good yield could be achieved with 2-ethynylthiophene as substrate (Table 2, 16). No conversion was observed for 2-ethynylpyridine and 2-ethynylaniline, presumably due to coordination of the nitrogen donor blocking the vacant coordination site of the active $\mathrm{Mn}(\mathrm{I})$ acetylide catalyst. 
Table 1. Optimization reaction for the dimerization of phenylacetylene catalyzed by 1.

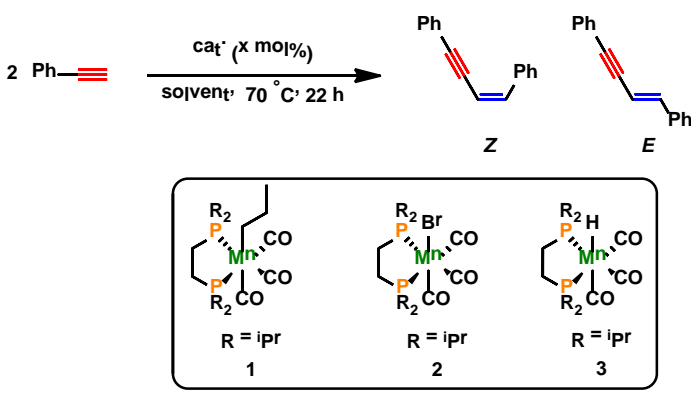

\begin{tabular}{lllll}
\hline entry & catalyst (mol\%) & solvent & conversion [\%] & $\mathbf{Z}:$ E ratio \\
\hline 1 & $1(2)$ & THF & $>99$ & $96: 4$ \\
2 & $2(2)$ & THF & - & n.d. \\
3 & $3(2)$ & THF & - & n.d. \\
4 & $1(2)$ & toluene & 17 & $95: 5$ \\
5 & $1(2)$ & $\mathrm{CHCl}_{3}$ & 12 & $97: 3$ \\
$\mathbf{6}^{\mathbf{a}}$ & $\mathbf{1}(\mathbf{1})$ & THF & $>\mathbf{9 9}$ & $\mathbf{9 7 : 3}$ \\
$7^{\mathrm{a}, \mathrm{b}}$ & $1(1)$ & $\mathrm{THF}$ & traces & n.d. \\
\hline
\end{tabular}

Reaction conditions: phenylacetylene $(1.1 \mathrm{mmol}), 0.5 \mathrm{~mL}$ anhydrous solvent, $70{ }^{\circ} \mathrm{C}, 22 \mathrm{~h}$, conversion and isomer ratio determined by GC-MS. ${ }^{\mathrm{a}} 18 \mathrm{~h} .{ }^{\mathrm{b}} 25^{\circ} \mathrm{C}$.

The investigation of aliphatic alkynes unveiled an unexpected observation. Apart from lower reactivity of aliphatic systems, which led to higher catalyst loadings and prolonged reaction times, the product changed drastically. Instead of head-to-head dimerization, massive formation of head-to-tail product and only small amounts of Z-1,3-enyne and no E-1,3-enyne were detected. Excellent yields could be achieved for linear aliphatic substrates such as 1-hexyne or 1-octyne (Table 3, 18 and 19). Lower reactivity was observed for 3-phenyl-1-propyne (Table 3, 22). Interestingly, a ratio of 39:61 gem:Z was observed for trimethylsilylacetylene (Table 3, 23). Cyclic aliphatic systems (Table 3, 24 - 26) gave excellent yields with high selectivity towards the geminal isomer.

Encouraged by these findings, we aimed for the cross-coupling of aromatic with aliphatic alkynes yielding geminal 1,3-enynes. Cross-coupling of alkynes is a challenging field due the high number of possible cross- and homo-coupling products. The results are represented in Table 4. A detailed table of all detected isomers is provided the SI. We were able to couple a variety of aromatic substrates with cyclopropylacetylene (Table 4, 27-30). The highest yields were achieved if electron donating groups, such as $t \mathrm{Bu}$ or $\mathrm{OMe}$ are present in the para-position. These substrates show lower tendency to dimerize under the given reaction conditions. Phenylacetylene and 1-chloro-4-phenylacetylene showed a higher amount of dimerization for the investigated systems, which lowers the amount of cross-coupling product. Good to excellent yields were achieved for the coupling of 4-ethynylanisole with 6-chloro-1-hexyne as well as 
1-ethynylcyclohexene. Furthermore, $\mathbf{1}$ is suitable for cross-coupling of two aliphatic substrates (cyclopropylacetylene and 1-ethynylcyclohexene, Table 4, 34).

Table 2. Scope and limitation of the dimerization of aromatic alkynes catalyzed by 1.

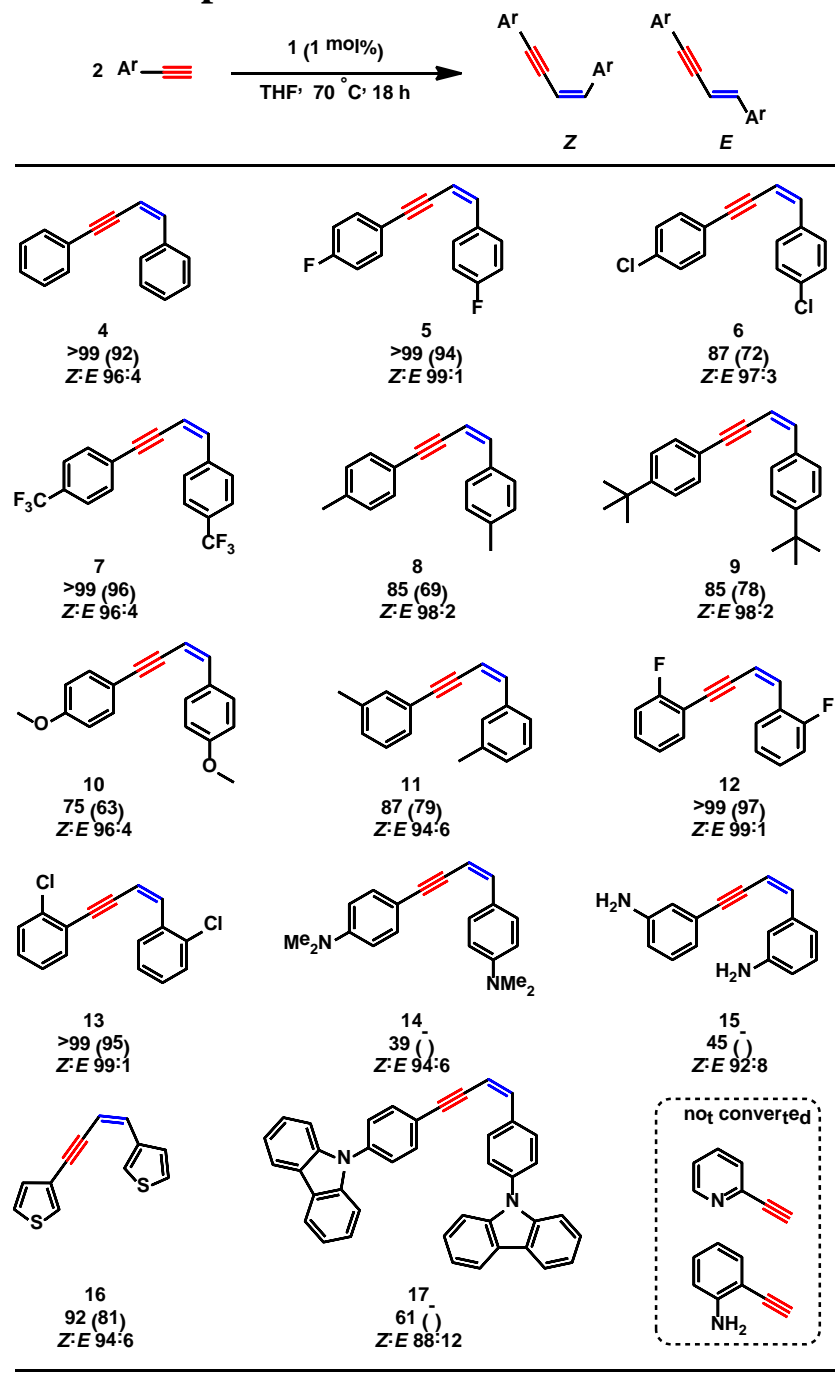

Reaction conditions: alkyne (1.1 mmol), 1 (1 mol\%), $0.5 \mathrm{~mL}$ anhydrous THF, $70{ }^{\circ} \mathrm{C}$, $18 \mathrm{~h}$, conversion and isomer ratio determined by GC-MS, isolated yield given in parenthesis.

The homogeneity of the system was confirmed upon addition of one drop of mercury, whereas no decrease of reactivity and selectivity was observed for the dimerization of phenylacetylene. In presence of 1 equivalent of $\mathrm{PMe}_{3}$, only traces of product formation could be detected, which indicates an inner-sphere mechanism. Kinetic isotope effects of 1.49 and 2.44 were detected for the dimerization of phenylacetylene $v s$. phenylacetylene- $d_{1}$ and 1-octyne vs. 1-octyne- $d_{1}$, respectively, as depicted in Scheme 2. 
Table 3. Scope and limitation of the dimerization of aliphatic alkynes catalyzed by 1 .
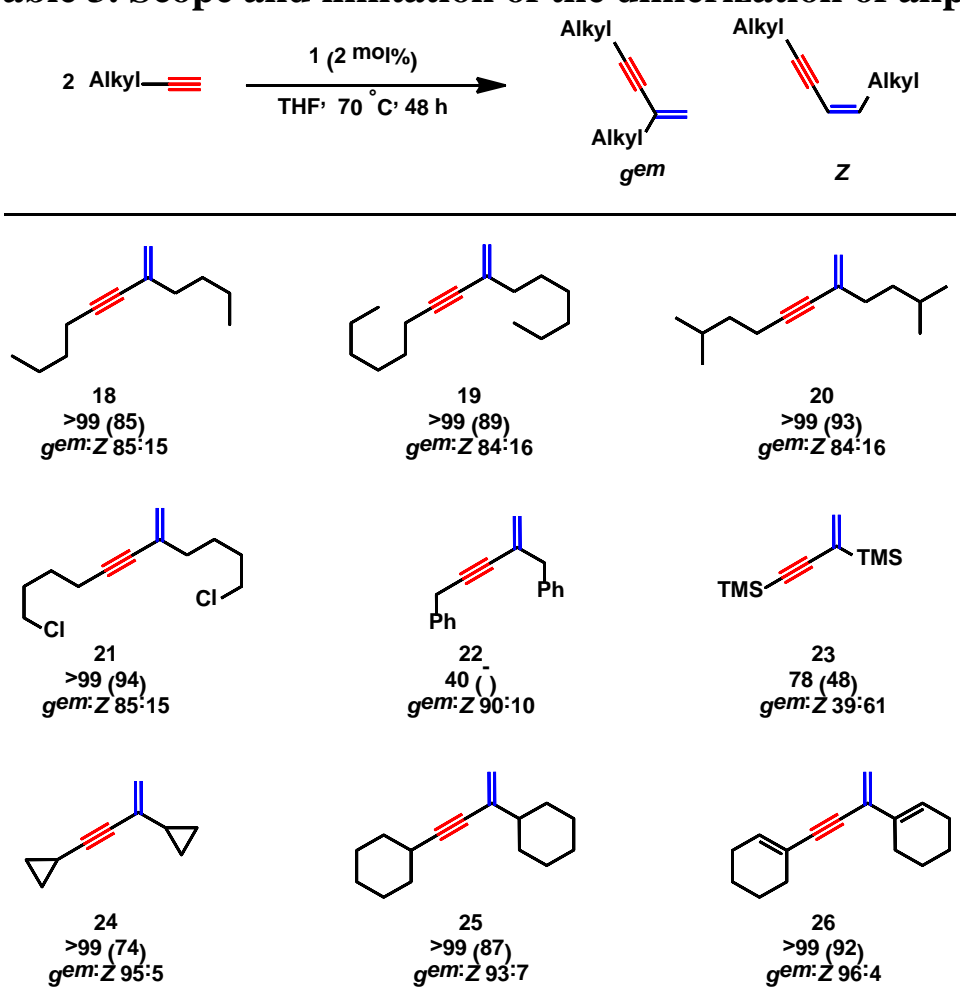

Reaction conditions: alkyne (1.1 mmol), 1 (2 mol\%), $0.5 \mathrm{~mL}$ anhydrous THF, $70{ }^{\circ} \mathrm{C}, 48 \mathrm{~h}$, conversion and isomer ratio determined by GC-MS, isolated yield given in parenthesis.

Table 4. Scope and limitation of the cross-coupling alkynes catalyzed by 1.

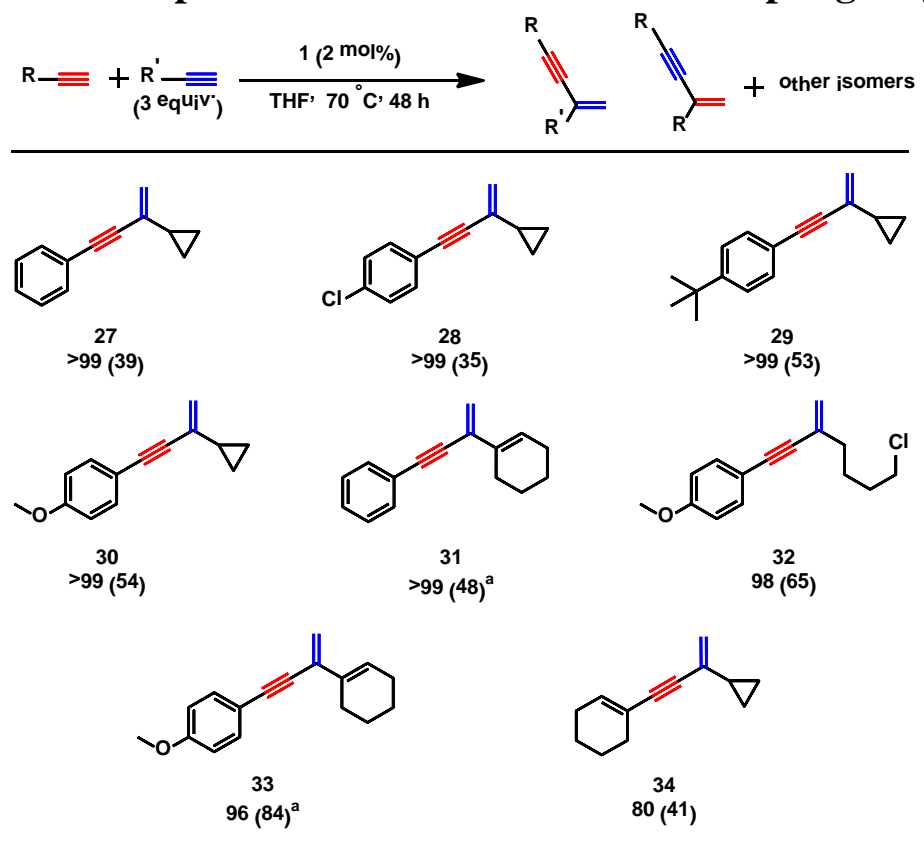

Reaction conditions: alkyne 1 (1.1 mmol, 1 equiv.), alkyne 2 (3.3 mmol, 3 equiv.), 1 (2 mol\%), $0.5 \mathrm{~mL}$ anhydrous THF, $70{ }^{\circ} \mathrm{C}, 48 \mathrm{~h}$, conversion of alkyne 1 determined by GC-MS, isolated yield given in parenthesis. ${ }^{a}$ Yield determined by GC-MS using hexadecane as standard. 
This suggests that the activation of the $\mathrm{C}-\mathrm{H}$ bond is the rate determining step during the reaction. These findings are in line with theoretical calculation since the $\mathrm{C}-\mathrm{H}$ activation upon product release shows the highest energy barrier in the catalytic reaction (vide infra). Interestingly, the ratio of gem:Z for 1-octyne$d_{1}$ is drastically increased to $97: 3$ (85:17 for 1-octyne).

Scheme 2. Determination of the KIE for the dimerization of phenylacetylene (a) and 1-octyne (b) catalyzed by 1 .
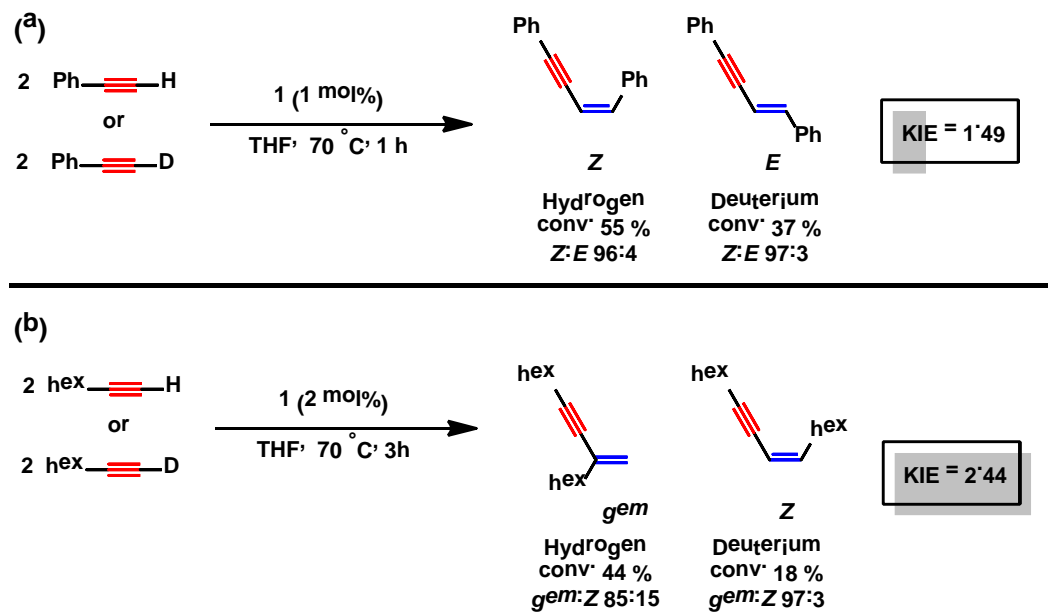

In order to get more insight into the dimerization of terminal alkynes, we performed DFT-calculations ${ }^{10}$ based on $f a c$ - $\left[\mathrm{Mn}\right.$ (dippe) $\left.(\mathrm{CO})_{3}\left(\mathrm{CH}_{2} \mathrm{CH}_{2} \mathrm{CH}_{3}\right)\right](\mathbf{1})$ as the pre-catalyst and employing phenylacetylene as the substrate. The free energy profile calculated for the formation of the active species, previous to the initiation of the catalytic cycle, is represented in Figure 1.

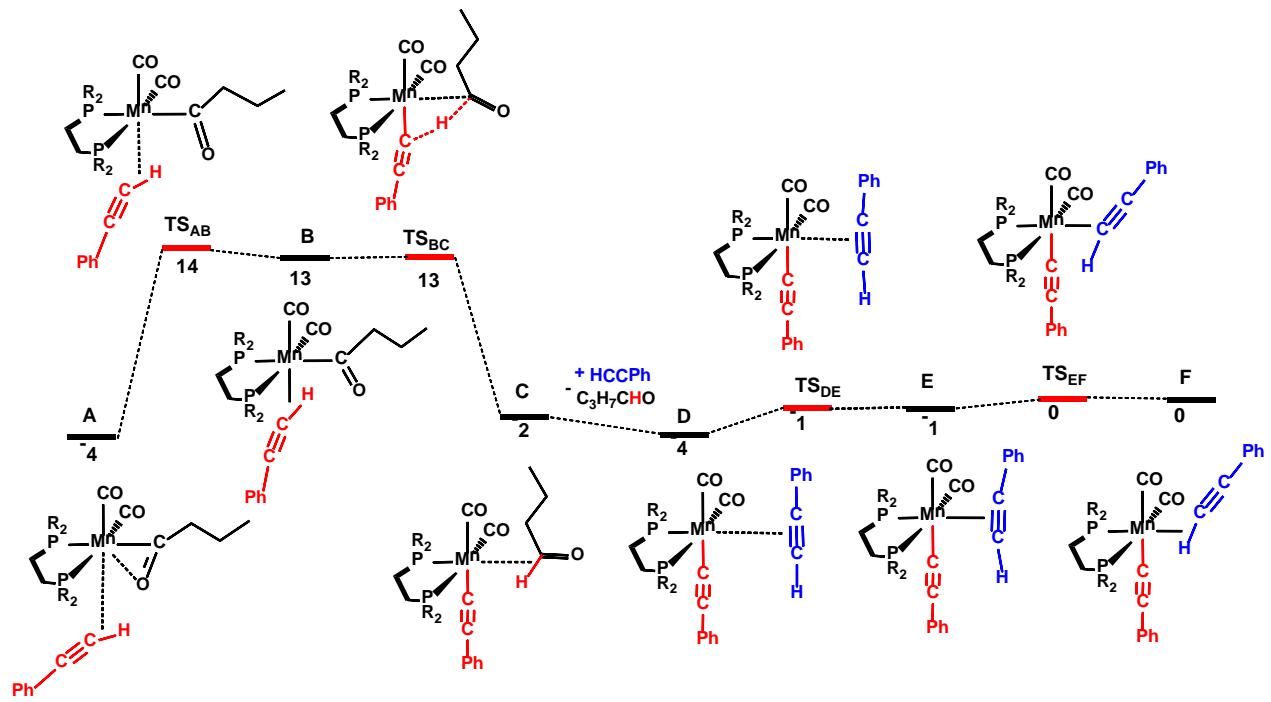

Figure 1. Free Energy Profile Calculated for the Formation of the Active Acetylide Catalyst. Free Energies $(\mathrm{kcal} / \mathrm{mol})$ are Referred to $\left[\mathrm{Mn}(\right.$ dippe $\left.)(\mathrm{CO})_{2}(\mathrm{C} \equiv \mathrm{CPh})\left(\eta^{2}-C, H-\mathrm{HC} \equiv \mathrm{CPh}\right)\right]$ (F in the calculations).

Catalyst initiation, starting from 1, has been reported previously. ${ }^{7}$ Experimental mechanistic studies revealed that $n$-butanal is liberated during the catalytic reaction as detected by ${ }^{1} \mathrm{H}$ - NMR spectroscopy. 
The first step following formation of an acyl intermediate is coordination of one phenylacetylene molecule, from $\mathbf{A}$ to $\mathbf{B}$, and, then, there is H-transfer from the newly bonded acetylene ligand to the carbonyl C-atom, with formation of aldehyde, from $\mathbf{B}$ to $\mathbf{C}$. This part of the path includes the highest barrier in the profile, $\Delta G^{\ddagger}=18 \mathrm{kcal} / \mathrm{mol}$, from $\mathbf{A}$ to $\mathbf{T S}$ AB.

From $\mathbf{C}$, butanal is liberated and exchanges with a second substrate molecule that slips from $\eta^{2}$ coordination in $\mathbf{E}$ to a $\kappa^{2}$-mode in $\mathbf{F}$. This is the initial active species in the catalytic cycle, and its formation follows a series of steps fairly easy $\left(\Delta G^{\ddagger}=4 \mathrm{kcal} / \mathrm{mol}\right)$ and almost thermoneutral $(\Delta G=2 \mathrm{kcal} / \mathrm{mol})$, from C to $\mathbf{F}$.

\section{Scheme 3. Simplified Catalytic Cycle for the (Z)-Selective Dimerization of Terminal Alkynes.}

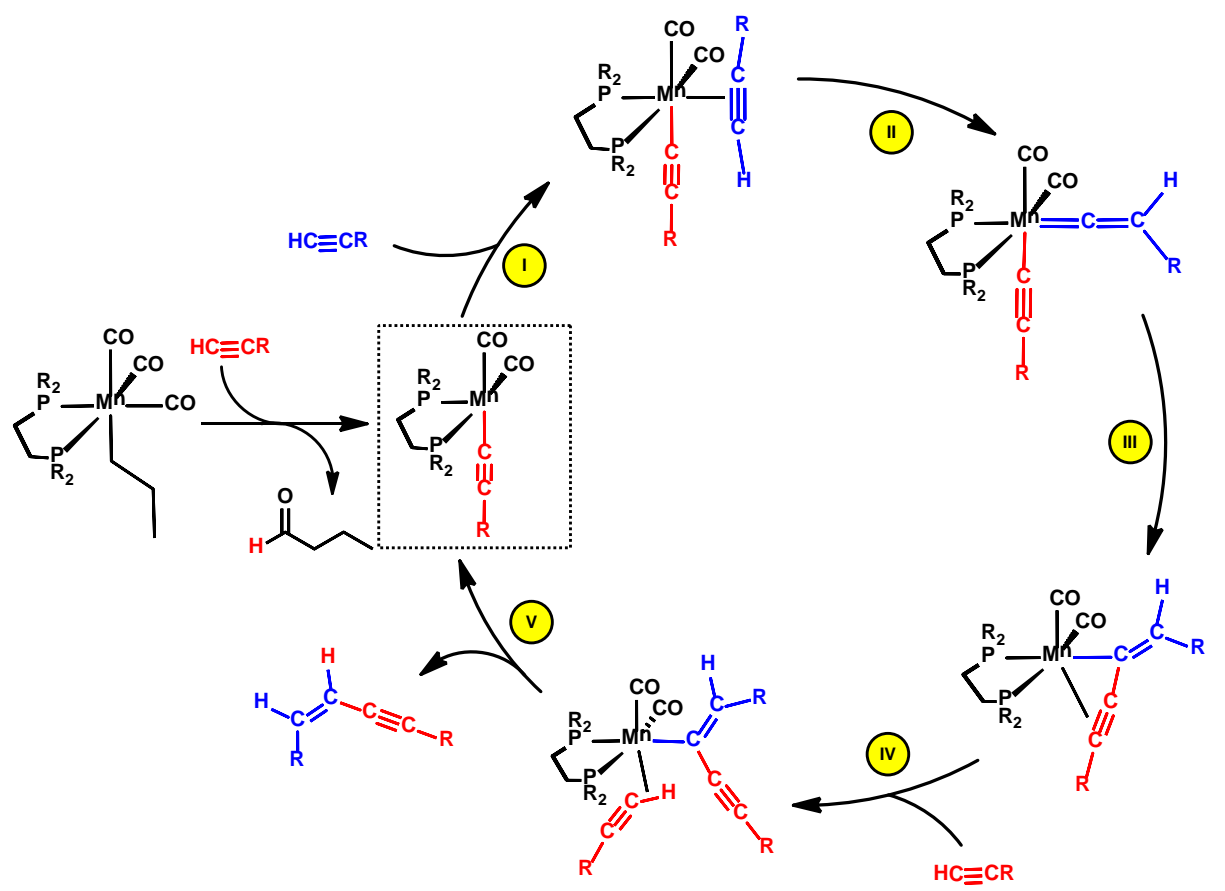

Scheme 3 depicts a summary of the catalytic cycle. Similarly to what is known for ruthenium- as well as iron-based systems, ${ }^{11,12,9 \mathrm{~g}}$ our calculations unveiled a classical acetylene-vinylidene mechanism. In particular, an incoming acetylene substrate undergoes a 1,2-H-shift (II) yielding a vinylidene intermediate which suffers nucleophilic attack from the neighboring acetylide ligand (III) resulting in the formation of an alkynyl vinyl complex. Proton transfer from a second acetylene molecule leads to the liberation the final 1,3-enyne and recovery of the initial acetylide species (IV, V).

The free energy profile obtained for the first part of the path (II and III in the cycle of Scheme 3) is represented in Figure 2. Here, formation of the two isomers of the alkynyl vinyl intermediate, with $Z$ and $E$ conformations around the $\mathrm{C}=\mathrm{C}$ double bond, is considered. Thus, the left part of the profile regards formation of the intermediate with the $E$-vinylalkynyl ligand, from $\mathbf{F}$ (the last species in the profile of Figure 1) to $\mathbf{H}_{\mathrm{E}}$. This is a single-step path, with simultaneous $\mathrm{H}$-shift on the acetylene ligand and $\mathrm{C}-\mathrm{C}$ coupling between this and the neighbor acetylide. The corresponding barrier is $\Delta G^{\ddagger}=15 \mathrm{kcal} / \mathrm{mol}$ and the process is favorable, from the thermodynamic point of view, with $\Delta G=-30 \mathrm{kcal} / \mathrm{mol}$.

The right-hand part of the profile in Figure 2 regards formation of the vinylalkynyl intermediate with this ligand in a Z-conformation, from $\mathbf{F}$ to $\mathbf{H z}$. In this case, the overall process takes two consecutive 
steps. First, there is $\mathrm{H}$-shift within the acetylene ligand, forming a vinylidene acetylide intermediate, from $\mathbf{F}$ to $\mathbf{G z}$, in an exergonic step $(\Delta G=-9 \mathrm{kcal} / \mathrm{mol})$ with a barrier of $\Delta G^{\ddagger}=13 \mathrm{kcal} / \mathrm{mol}\left(\mathbf{T S}^{\mathbf{Z}}{ }_{\mathbf{F G}}\right)$. Then, in a second step, there is $\mathrm{C}-\mathrm{C}$ coupling between the two ligands, the vinylidene and the acetylide, from $\mathbf{G z}$ to $\mathbf{H z}$, in a facile step with a barrier of only $\Delta G^{\ddagger}=4 \mathrm{kcal} / \mathrm{mol}$ (from $\mathbf{G z}$ to $\mathbf{T S}^{\mathbf{Z}} \mathbf{G H}$ ) and a balance of $\Delta G=$ $-26 \mathrm{kcal} / \mathrm{mol}$.

From the profile in Figure 2, it is clear that the Z-alkynylvinyl intermediate $(\mathbf{H z})$ is the most stable of the two isomers by $5 \mathrm{kcal} / \mathrm{mol}$ and also the one that is formed more easily, with a barrier $2 \mathrm{kcal} / \mathrm{mol}$ lower

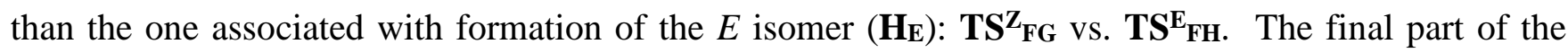
mechanism corresponds to the formation of the 1,3-enyne product from the alkynylvinyl intermediates (IV and $\mathbf{V}$ in the cycle of Scheme 3). The corresponding free energy profile is represented in Figure 3 for the two isomers, $Z$ and $E$. The left hand side of the profile concerns formation of the $E$-enyne (in $\mathbf{K}_{\mathbf{E}}$ ) from the corresponding $E$ - alkynylvinyl intermediate $\left(\mathbf{H}_{\mathbf{E}}\right)$, while on the right side there is the equivalent profile for the formation of the product with a $Z$ conformation, from $\mathbf{H z}$ to $\mathbf{K z}$. Two equivalent mechanisms were obtained, both composed by two steps: first coordination of a new phenylacetylene molecule and, then, $\mathrm{H}$-transfer from coordinated acetylene to the alkynylvinyl ligand with formation of the product. The barrier associated with the formation of the Z-enyne ( $\Delta G^{\ddagger}=25 \mathrm{kcal} / \mathrm{mol}$, from $\mathbf{H z}$ to $\mathbf{T S}^{\mathbf{Z}} \mathbf{I J}$ or $\left.\mathbf{T S}^{\mathbf{Z}} \mathbf{J K}\right)$ is $7 \mathrm{kcal} / \mathrm{mol}$ lower than the one corresponding to the formation of its $E$-counterpart indicating that the $Z$ isomer is the most favorable product, as observed. Interestingly, the last step (associated with $\mathbf{T S}^{\mathbf{Z}} \mathbf{J K}$ ) corresponds to H-transfer and being the rate-determining step corroborates the kinetic isotopic effect experimentally detected and discussed above (see Scheme 2).

The mechanism of $Z-E$ isomerization between the two forms of the alkynylvinyl intermediates $\left(\mathbf{H}_{\mathbf{E}}\right.$ and $\mathbf{H z}$ ) was also studied and the profile obtained is presented in the SI. The corresponding rearrangement around the $\mathrm{C}=\mathrm{C}$ double bond of the ligand has an overall barrier of $\Delta G^{\ddagger}=24 \mathrm{kcal} / \mathrm{mol}$ that, being 1 $\mathrm{kcal} / \mathrm{mol}$ lower than the one calculated for the catalytic cycle, indicates that the isomerization process is faster, or at least competitive, compared with enyne formation.

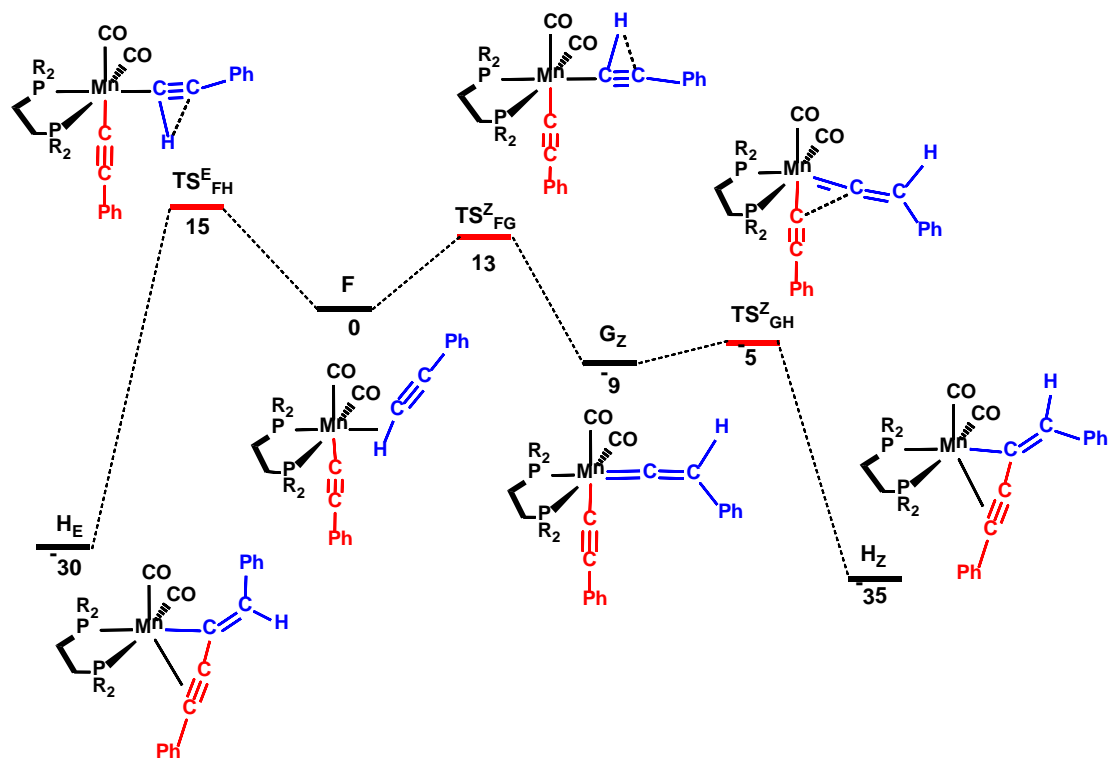

Figure 2. Free Energy Profile Calculated for the Dimerization of Terminal Alkynes. Free Energies (kcal/mol) are Referred to $\left[\mathrm{Mn}(\operatorname{dippe})(\mathrm{CO})_{2}(\mathrm{C} \equiv \mathrm{CPh})\left(\eta^{2}-\mathrm{HC} \equiv \mathrm{CPh}\right)\right](\mathbf{F}$ in the calculations) 


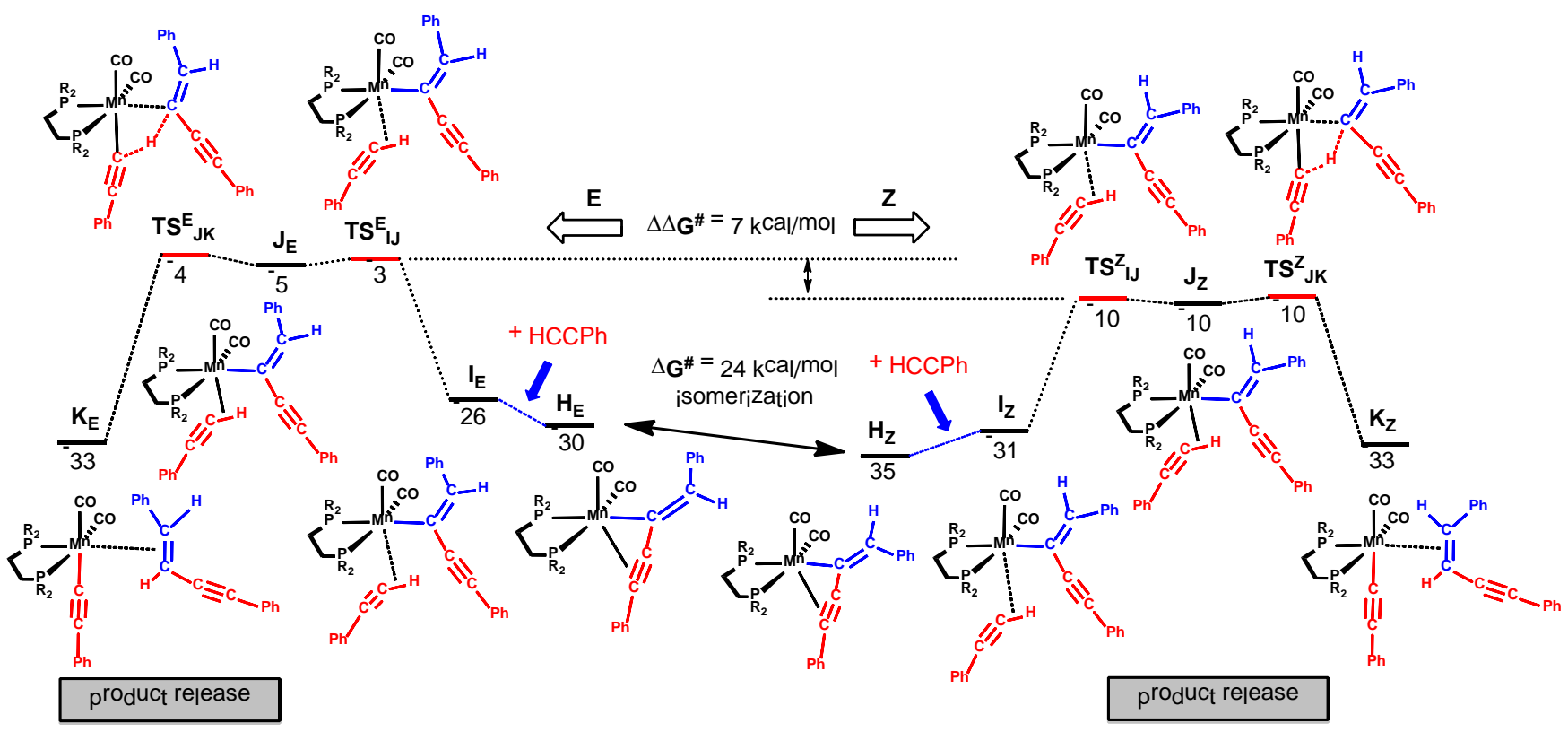

Figure 3. Free Energy Profile Calculated for the Dimerization of Terminal Alkynes. Free Energies (kcal/mol) are Referred to $\left[\mathrm{Mn}(\operatorname{dippe})(\mathrm{CO})_{2}(\mathrm{C} \equiv \mathrm{CPh})\left(\eta^{2}-\mathrm{HC} \equiv \mathrm{CPh}\right)\right]$ (F in the calculations)

\section{CONCLUSION}

In sum, an efficient and highly selective additive-free manganese-catalyzed dimerization and crosscoupling of terminal alkynes to afford enynes is described. To the best of our knowledge, this is the first example of a well-defined $\mathrm{Mn}(\mathrm{I})$-based catalyst for such a process. The pre-catalyst is the alkyl bisphosphine $\mathrm{Mn}(\mathrm{I})$ complex fac-[Mn(dippe) $\left.(\mathrm{CO})_{3}\left(\mathrm{CH}_{2} \mathrm{CH}_{2} \mathrm{CH}_{3}\right)\right]$ (1) which is air-stable for several weeks in the solid state. The initiation step involves migratory insertion of a CO ligand into the Mn-alkyl bond followed by $\mathrm{C}-\mathrm{H}$ bond activation of the terminal alkyne to form the $16 \mathrm{e}^{-} \mathrm{Mn}(\mathrm{I})$ acetylide complex $\left[\mathrm{Mn}(\right.$ dippe $\left.)(\mathrm{CO})_{2}(\mathrm{HC} \equiv \mathrm{CR})\right]$. This species is an efficient catalyst for the regio- and stereoselective headto-head dimerization of terminal aromatic and aliphatic alkynes giving 1,3-enynes and head-to-tail gem1,3-enynes, respectively, in high yields with up to 99\% selectivity. Additionally, complex 1 is also capable to promote cross-dimerizations of aromatic with aliphatic alkynes yielding geminal 1 1,3-enynes. DFT calculations disclosed in the case of aromatic alkynes an acetylene-vinylidene mechanism and indicate that the Z-1,3-enyne is a kinetic product, resulting from a lower energy barrier, compared with the one associated with the formation of its E-counterpart as depicted in Scheme 2. Based on the kinetic isotope effects of 1.49 and 2.44 detected for the dimerization of phenylacetylene vs. phenylacetylene- $d_{1}$ and 1octyne vs. 1-octyne- $d_{1}$, respectively, the activation of the $\mathrm{C}-\mathrm{H}$ bond appears to be the rate determining step. These findings are in line with theoretical calculation since the $\mathrm{C}-\mathrm{H}$ activation upon product release shows the highest energy barrier in the catalytic reaction.

\section{Supporting Information}

${ }^{1} \mathrm{H}$ - and ${ }^{13} \mathrm{C}\left\{{ }^{1} \mathrm{H}\right\}$-NMR spectra of all compounds and complete computational details (PDF) Cartesian coordinates for DFT-optimized structures (XYZ) 


\section{ACKNOWLEDGMENT}

Financial support by the Austrian Science Fund (FWF) is gratefully acknowledged (Project No. P 33016N). Centro de Química Estrutural acknowledges the financial support of Fundação para a Ciência e Tecnologia (UIDB/00100/2020).

\section{REFERENCES}

(1) Calderazzo, F. Synthetic and Mechanistic Aspects of Inorganic Insertion Reactions. Insertion of Carbon Monoxide. Angew. Chem. Int. Ed. 1977, 16, 299-311.

(2) (a) Coffield, T. H.; Closson, R. D.; Kozikowski, J. Acyl Manganese Pentacarbonyl Compounds. J. Org. Chem. 1957, 22, 598. (b) Noack, K.; Calderazzo, F. Carbon monoxide insertion reactions. V. The carbonylation of methylmanganese pentacarbonyl with carbon-13 monoxide. J. Organomet. Chem. 1967, 10, 101-104.

(3) Casey, C. P.; Bunnell, C. A.; Calabrese, J. C. Synthesis, Crystal Structure, and Stability of Pyruvoylpenta-carbonylmanganese(I). J. Am. Chem. Soc. 1976, 98 ,1166-1171 and references therein.

(4) Food, T. C.; Jensen, J. E.; Staller, J. A. Stereochemistry at Manganese of the Carbon Monoxide Insertion in Pentacarbonylmethylmanganese(I). The Geometry of the Intermediate J. Am. Chem. Soc. 1981, 103, 4410-4414.

(5) Birbeck, J. M.; Haynes, A.; Adams, H.; Damoense, L.; Otto, S. Ligand Effects on Reactivity of Cobalt Acyl Complexes. ACS Catal. 2012, 2, 2512-2523.

(6) (a) Ojima, I.; Tsai, C.-Y.; Tzamarioudaki, M.; Bonafoux, D. The Hydroformylation Reaction; Wiley: New York, 2004. (b) van Leeuwen, P. W. N. M. In Homogeneous Catalysis: Understanding the Art; 1st ed.; Springer: Dordrecht, 2005. (c) Claver, C.; van Leeuwen, P. W. N. M. In Rhodium Catalyzed Hydroformylation; Claver, C., van Leeuwen, P. W. N. M., Eds.; Kluwer Academic Publishers: Dordrecht, The Netherlands, 2000.

(7) (a) Weber, S.; Veiros, L. F.; Kirchner, K. Old Concepts, New Application: Additive-free Hydrogenation of Nitriles Catalyzed by a Bench-Stable Alkyl Mn(I) Complex. Adv. Synth. Catal. 2019, 361, 5412-5420. (b) Weber, S.; Stöger, B.; Veiros, L. F.; Kirchner, K. Rethinking Old Concepts Hydrogenation of Alkenes Catalyzed by Bench-Stable Alkyl Mn(I) Complexes. ACS Catal. 2019, 9, 9715-9720.

(8) Liang, Q.; Hayashi, K.; Song, D. Catalytic Alkyne Dimerization without Noble Metals. ACS Catal. 2020, 10, 4895-4905.

(9) For recent examples of base-metal catalyzed alkyne dimerizations, see: (a) Midya, G. C.; Paladhi, S.; Dhara, K.; Dash, J. Iron Catalyzed Highly Regioselective Dimerization of Terminal Aryl Alkynes. Chem. Commun. 2011, 47, 6698-6700. (b) Midya, G. C.; Parasar, B.; Dhara, K.; Dash, J. Ligand Mediated Iron Catalyzed Dimerization of Terminal Aryl Alkynes: Scope and Limitations. Org. Biomol. Chem. 2014, 12, 1812-1822. (c) Bhunia, M.; Sahoo, S. R.; Vijaykumar, G.; Adhikari, D.; Mandal, S. K. Cyclic (Alkyl)amino Carbene Based Iron Catalyst for Regioselective Dimerization of Terminal Arylalkynes. Organometallics 2016, 35, 3775-3780. (d) Xue, F.; Song, X.; Lin, T. T.; Munkerup, K.; Albawardi, S. F.; Huang, K.-W.; Hor, T. S. A.; Zhao, J. Dimerization of Terminal Aryl Alkynes Catalyzed by Iron(II) Amine-Pyrazolyl Tripodal Complexes with E/Z Selectivity Controlled by tert-Butoxide. ACS Omega 2018, 3, 5071-5077. (e) Rivada-Wheelaghan, O.; Chakraborty, S.; Shimon, L. J. W.; Ben-David, Y.; Milstein, D. Z-Selective (Cross-) Dimerization of Terminal Alkynes Catalyzed by an Iron Complex. Angew. Chem., Int. Ed. 2016, 55, 6942-6945. (f) Gorgas, N.; Alves, L. G.; Stöger, B.; Martins, A. M.; 
Veiros, L. F.; Kirchner, K. Stable, Yet Highly Reactive Nonclassical Iron(II) Polyhydride Pincer Complexes: Z-Selective Dimerization and Hydroboration of Terminal Alkynes. J. Am. Chem. Soc. 2017, 139, 8130-8133. (g) Gorgas, N.; Stöger, B.; Veiros, L. F.; Kirchner, K. Iron(II) Bis(acetylide) Complexes as Key Intermediates in the Catalytic Hydrofunctionalization of Terminal Alkynes. ACS Catal. 2018, 8, 7973-7982. (h) Liang, Q.; Osten, K. M.; Song, D. Iron-Catalyzed gem-Specific Dimerization of Terminal Alkynes. Angew. Chem., Int. Ed. 2017, 56, 6317-6320. (i) Liang, Q.; Sheng, K.; Salmon, A.; Zhou, V. Y.; Song, D. Active Iron(II) Catalysts toward gem-Specific Dimerization of Terminal Alkynes. ACS Catal. 2019, 9, 810-818. (j) Field, L. D.; Ward, A. J.; Turner, P. The Dimerization and Cyclotrimerization of Acetylenes Mediated by Phosphine Complexes of Cobalt(I), Rhodium(I), and Iridium(I). Aust. J. Chem. 1999, 52, 1085-1092. (k) Hilt, G.; Hess, W.; Vogler, T.; Hengst, C. Ligand and Solvent Effects on Cobalt(I)-Catalysed Reactions: Alkyne Dimerisation Versus [2+2+2]-Cyclotrimerisation Versus Diels-Alder Reaction Versus [4+2+2]-Cycloaddition. J. Organomet. Chem. 2005, 690, 5170-5181. (l) Beattie, J. W.; Wang, C.; Zhang, H.; Krogman, J. P.; Foxman, B. M.; Thomas, C. M. Dimerization of Terminal Alkynes Promoted by a Heterobimetallic Zr/Co Complex. Dalton Trans. 2020, 49, 2407-2411. (m) Xu, D.; Sun, Q.; Quan, Z.; Wang, C.; Sun, W. Cobalt-Catalyzed Dimerization and Homocoupling of Terminal Alkynes. Asian J. Org. Chem. 2018, 7, 155-159. (n) Zhuang, X.; Chen, J.-Y.; Yang, Z.; Jia, M.; Wu, C.; Liao, R.-Z.; Tung, C.-H.; Wang, W. Sequential Transformation of Terminal Alkynes to 1,3Dienes by a Cooperative Cobalt Pyridonate Catalyst. Organometallics 2019, 38, 3752-3759. (o) GrenierPetel, J.-C.; Collins, S. K. Photochemical Cobalt-Catalyzed Hydroalkynylation To Form 1,3-Enynes. ACS Catal. 2019, 9, 3213-3218. (p) Ueda, Y.; Tsurugi, H.; Mashima, K. Cobalt-Catalyzed (E)-Selective Cross-Dimerization of Terminal Alkynes via a Mechanism Involving Co(0/II) Redox Cycles. Angew. Chem., Int. Ed. 2020, 59, 1552-1556. (q) Chen, J.-F.; Li, C. Cobalt-Catalyzed gem-Cross-Dimerization of Terminal Alkynes. ACS Catal. 2020, 10, 3881-3889.

(10) (a) Parr, R. G.; Yang, W. Density Functional Theory of Atoms and Molecules; Oxford University Press: New York, 1989. (b) Calculations performed at the M06/(6-311++G**)//PBE0/(SDD,6-31G**) level using the GAUSSIAN 09 package. Single-point energy calculations included solvent effects (benzene) using the PCM/SMD model. A full account of the computational details and a complete list of references are provided as $\mathrm{SI}$.

(11) (a) Jia, G.; Meek, D. W.; Gallucci, J. C. Synthesis and Reactivity of Ruthenium Hydride Complexes Containing Chelating Triphosphines. 4. Reactions of Ruthenium Hydride Complexes Containing Triphosphines with Olefins. Organometallics 1990, 9, 2549-2555. (b) Bianchini, C.; Peruzzini, M.; Zanobini, F.; Frediani, P.; Albinati, A. A Ruthenium(II) Enynyl Complex Mediates the Catalytic Dimerization of 1-Alkynes to Z-1,4-Disubstituted Enynes. J. Am. Chem. Soc. 1991, 113, 5453-5454. (c) Jia, G.; Meek, D. W. Synthesis and Reactivity of Ruthenium Hydride Complexes of Chelating Triphosphines. 5. Reactions of Acetylenes with RuHCl(Cyttp) and $\mathrm{RuH}_{4}(\mathrm{Cyttp})$ (Cyttp = $\mathrm{C}_{6} \mathrm{H}_{5} \mathrm{P}\left[\mathrm{CH}_{2} \mathrm{CH}_{2} \mathrm{CH}_{2} \mathrm{P}\left(\mathrm{c}-\mathrm{C}_{6} \mathrm{H}_{11}\right)_{2}\right]_{2}$ \}. Organometallics 1991, 10, 1444-1450. (d) Eaves, S. G.; Yufit, D. S.; Skelton, B. W.; Lynam, J. M.; Low, P. J. Reactions of alkynes with cis- $\mathrm{RuCl}_{2}(\mathrm{dppm})_{2}$ : exploring the interplay of vinylidene, alkynyl and $\eta^{3}$-butenynyl complexes. Dalton Trans. 2015, 44, 21016-21024.

(12) Katayama, H.; Ozawa, F. Vinylidene Ruthenium Complexes in Catalysis. Coord. Chem. Rev. 2004, 248, 1703-1715. 